\title{
Determining seasonal displacements of Earth's crust in South America using observations from space-borne geodetic sensors and surface-loading models
}

Vagner G. Ferreira ${ }^{1 *}\left(\mathbb{D}\right.$, Henry D. Montecino ${ }^{2}$, Christopher E. Ndehedehe ${ }^{3}$, Rodrigo A. del Rio ${ }^{4}$, Aharon Cuevas ${ }^{2}$ and Silvio R. C. de Freitas ${ }^{5}$

\begin{abstract}
There are small pieces of evidence, suggesting that South America's hydrological cycle is changing, which impacts its water availability and, consequently, the Earth's surface due to its elastic response to the surface mass loading/ unloading. Therefore, we analyzed 3 to 15 years of vertical crustal displacements (VCDs) due to mass loadings using 292 Global Positioning System (GPS) stations in South America, which are essential for studies related to tectonic phenomena, for example. Thus, we investigated whether the intra-annual variabilities of the displacements could be reduced using modeled VCDs and inverted displacements from Gravity Recovery and Climate Experiment (GRACE) harmonic solutions (Release 06). The modeled VCDs come from the combination of nontidal atmospheric and ocean loadings with the hydrological loadings from the land-surface model (GLDAS) and reanalysis (MERRA). We found that the highest amplitudes of VCDs of the annual signals are concentrated mainly over the Amazon Rainforest and Brazilian Highlands. However, the results also show different behavior throughout other physiographic provinces of South America, which shows low water capabilities as "sensed" by GRACE and described by the GLDAS and MERRA models. Accordingly, when we disregard the stations over the Andes Mountains and Patagonia in the analysis, the highest reduction in the variability of GPS-observed VCDs is achieved while using GRACE (79\% of the sites), MERRA (75\% of the sites), and GLDAS (74\% of the sites). For these stations, the amplitudes (and phases) of the annual signals depicted by the geodetic sensors generally agree, while those from GLDAS and MERRA explain only approximately $50 \%$ of the deformation. However, in the southwest region of South America (between the latitude bands of $-40^{\circ}$ to $-30^{\circ}$ ), GPS annual signals, which reached up to $11 \mathrm{~mm}$, are much larger than those from GRACE and the models due to the existence of lakes that are not resolved in global analysis. These inconsistencies between GPS-observed VCDs and those derived from GRACE and the other models require further investigation, specifically for Chile.
\end{abstract}

Keywords: South American, radial deformation, Surface-loading models, GPS, GRACE, Loading

\footnotetext{
*Correspondence: vagnergf@hhu.edu.cn

${ }^{1}$ School of Earth Sciences and Engineering, Hohai University, Nanjing,

China

Full list of author information is available at the end of the article
} 


\section{Introduction}

South America is known for its complex dynamic processes related to topographical, geological, geophysical, hydrological, and climate features (Hinze et al. 1982; Hughes et al. 2009; Solman 2013; Flament et al. 2015; Novello et al. 2018). For example, the continent is of interest in investigating the magnitude and distribution of crustal deformations and their implications in different fields of study, such as geodesy, hydrology, geophysics, and climate change (e.g., Ferreira et al. 2018). First, this is because of the critical rates of crustal deformation in the Andes dominated by the different phases and wavelengths of the earthquake deformation cycle (Khazaradze and Klotz 2003; Melnick et al. 2017). Second, the continent has the largest availability of water resources in the world. Moreover, South America also hosts some of the world's regions with the highest water scarcity (e.g., Buytaert and Breuer 2013) and exhibits diverse patterns of weather and climate features (e.g., Eichler and Londoño 2013).

Crustal deformations of South America have been investigated in the last two decades using geodetic observations over specific regions (see, e.g., Bevis et al. 2004, 2005; Davis et al. 2004; Galván et al. 2015; Moreira et al. 2016). However, despite the importance of understanding the effect of surface mass loadings, no study has thoroughly investigated the associated vertical crustal deformation (VCD) variability in the continent's broadscale domain. Currently, the primary techniques for measuring the VCDs include the Global Positioning System (GPS) and, less frequently due to their necessary complex infrastructure and high costs, Doppler orbitography and radio-positioning integrated by satellite, satellite laser ranging, and very long baseline interferometry. Among all space geodesy techniques dedicated to positioning, only GPS is widespread through South America (e.g., Jin and Zhu 2003; Ray et al. 2007).

Nevertheless, the geodetic techniques mentioned above are insufficient by themselves for recovering individual local loadings due to mass transport phenomena in the atmosphere, ocean, cryosphere, and continental hydrology. Thus, the Gravity Recovery and Climate Experiment (GRACE) and the combined loading models (CLMs) - a combination of nontidal atmosphere and ocean loadings and continental water storage loading-have become suitable datasets for modeling VCDs induced by the different surface mass variations. Several studies have been conducted in areas with strong hydrological signals using GRACE and GPS techniques to determine VCDs (see, e.g., Fu et al. 2012; Chanard et al. 2014; Tiwari et al. 2014; Pan et al. 2016).

For example, Hao et al. (2016) found a high correlation between GRACE-derived seasonal VCDs and those from
GPS-modeled annual and semiannual displacements across the southeastern Tibetan Plateau, which mainly reflected the hydrological loadings. Likewise, consistent seasonal movements between GPS and GRACE have been demonstrated in West Africa (Nahmani et al. 2012), the Nepal Himalayas (Fu and Freymueller 2012), and in China (Hai-hua et al. 2010). In particular, Gu et al. (2017) have found that the VCDs captured by GPS, GRACE, and CLMs demonstrate high consistency at 224 continuous GPS stations across China. Accordingly, Li et al. (2016) have found that the annual variability from GRACE, compared to the loading models, better explains the annual signal in the global set of GPS stations considered in their study. Nevertheless, Li et al. (2015) found that of the 344 selected global stations that belong to the International Global Navigation Satellite Systems Service (IGS), more than $77 \%$ have their variability reduced in the weekly GPS series by using surface-loading models. Using inputs from the revised version of the Modern-Era Retrospective Analysis for Research and Applications (MERRA), termed MERRA-Land (Reichle et al. 2011), and from Global Land Data Assimilation System (GLDAS)-Noah (Rodell et al. 2004) data, the best improvements determined to be from stations across North America and Eurasia.

Many studies have highlighted the importance of the hydrology of South America in the GRACE data variability (e.g., Humphrey et al. 2016), which makes this region an exclusive case study for the development of new methodologies (Ramillien et al. 2011). Although the relationship between GPS and GRACE has been studied globally with highlights on the role of South America (e.g., Tregoning et al. 2009), few have investigated the overall performance of GPS, GRACE, and CLMs in the different physiographic regions for the determination of VCDs altogether. For example, Davis et al. (2004) have found a high correlation of annual hydrological variations between GRACE and GPS-derived VCDs over the Amazon River Basin. The study conducted by Moreira et al. (2016) compared the hydrological loading from GPS, GRACE, and a deflection model related to surfaceloading effects also in the Amazon River Basin. Additionally, a related study by Galván et al. (2015) was based only on 34 stations using multiannual GPS time series provided by the South American Geocentric Reference System (SIRGAS) and the surface-loading information from GRACE. Notably, SIRGAS is a densification of the International Terrestrial Reference Frame (ITRF) and, as such, it is of paramount importance for the determination of the velocities of tectonic plates (cf., Sánchez and Drewes 2016). Since some regions of the continent are facing decreases (e.g., Eastern Brazil) and increases (Amazon Basin) in the continental water storage variability (Rodell 
et al. 2018; Getirana 2016; Sun et al. 2016a), the stability of the coordinates is influenced by these changes.

Therefore, this study investigates the performance of GRACE-derived VCDs and those based on CLMs (MERRA-Land and GLDAS-Noah) to reduce the variability in a GPS time series over South America. First, our contribution emphasizes the creation and presentation of a new extensive database containing 292 GPS stations distributed all over South America covering the years 2002 through 2016. This new database allowed us for the first time to determine and analyze the VCDs in all physiographic provinces of South America (e.g., Brazilian Highlands and Andes Mountains). Second, we emphasized the presentation of the performance of this new database when compared with the VCDs inverted from GRACE monthly solutions and those based on CLMs on an annual time scale. Intra-annual (seasonal) analysis is essential to update the coordinates in the context of SIRGAS, for example, since it could impact the coordinates' long-term stability if comparing different seasons.

To this end, we structured the remainder of this study as follows: "Materials and methods" section presents a description of the datasets and methods, followed by the results in "Results" section. In "Discussion" section, the discussions of the results are presented, which is followed by a summary and our conclusions in "Conclusions" section.

\section{Materials and methods GPS time series}

We used the time series data of 292 GPS stations located in South America (Fig. 1) from the Nevada Geodetic Laboratory (NGL) data processing (Blewitt et al. 2018). The data processing model used by NGL is precise point positioning with ambiguities resolution performed with GIPSY/OASIS-II (version 6.1.1). For GPS data processing, the NGL used the GPS fiducial-free orbit products of Jet Propulsion Laboratory-JPL (Bertiger et al. 2010) and applied the models as recommended by the conventions of the International Earth Rotation and Reference Systems Service-IERS (Gérard and Luzum 2010). The global mapping function (Boehm et al. 2006) was used to model the tropospheric refractivity by applying humid zenith tropospheric delay and horizontal gradients estimated as stochastic parameters every 5 min (Bar-Sever et al. 1998).

The motions of the station due to the oceanic loading (tidal) were calculated using the coefficients given by the ocean-tide-loading provider hosted at Chalmers University (Scherneck 1991), which applied the FES2004 tidal model. It is noteworthy that the total effects of atmospheric (tidal and nontidal) and nontidal oceanic loading reductions were not available while processing the GPS data and needed to be handled as post-processing procedures. Here, we considered the correction for atmospheric tide loading based on the amplitude and phase of the predicted deformation of the $S_{1}$ (diurnal) and $S_{2}$ (semidiurnal), which were based on the proposed IERS conventions (van Dam and Ray 2010). Overall, this correction due to the diurnal and semidiurnal atmospheric tidal deformations reached values of approximately $1.2 \mathrm{~mm}$ and $0.2 \mathrm{~mm}$ at stations near the latitudes $0^{\circ}$ and $55^{\circ} \mathrm{S}$, respectively. This has been reported by Jin et al. (2008), among others. Finally, the ambiguity resolution was applied to the double differences of the estimated one-way bias parameters (Blewitt 1989), using the widelane and phase bias method, which connects individual stations to the stations of the IGS as further described by Bertiger et al. (2010).

The final daily solutions are linked to the geodetic reference frame of the IGS08, which is derived from the latest release of the ITRF 2008 (ITRF2008) as further explained by Rebischung et al. (2012), and both frames share the same underlying origin, scale, and orientation. The ITRF2008 origin is defined in such a way that it has no net translational motion regarding the mean of the satellite laser ranging (SLR) time series (Altamimi et al. 2011). Given that the SLR is a good sensor of center of mass (CM) of the total Earth system, that is, the solid Earth and its fluid envelope (Dong et al. 2003), the origin of the IGS08 resembles the CM frame in the longterm sense. However, for seasonal and other short time scales, the origin of the IGS08 is indistinguishable from the center-of-figure (CF) frame as it is considered here, since we removed from the daily positions the long-term trends and offsets ("Analysis of VCD time series" section).

The observation period spans from June 2002 through February 2016, and all GPS time series are greater than 3 years in length (the majority has more than 7 years) with less than 3 months of missing data. The average error for the observed VCDs at each GPS station used does not exceed $5 \mathrm{~mm}$, and $90 \%$ of them do not exceed $3 \mathrm{~mm}$. Furthermore, outliers were removed based on the 3- $\sigma$ rule. Finally, the daily series were averaged on a monthly basis, regardless of whether full or partial monthly data were used in creating the GRACE monthly gravity field. This is necessary to allow a comparison of GPS with results from GRACE and CLMs.

\section{Vertical displacements inverted from GRACE solutions}

We used data corresponding to 163 GRACE monthly solutions between April 2002 and June 2017, which are represented in a set of spherical harmonic coefficients provided by the Center for Space Research (CSR), the University of Texas at Austin (Save et al. 2018), in its Release 06 up to degree and order 96. Because GRACE 


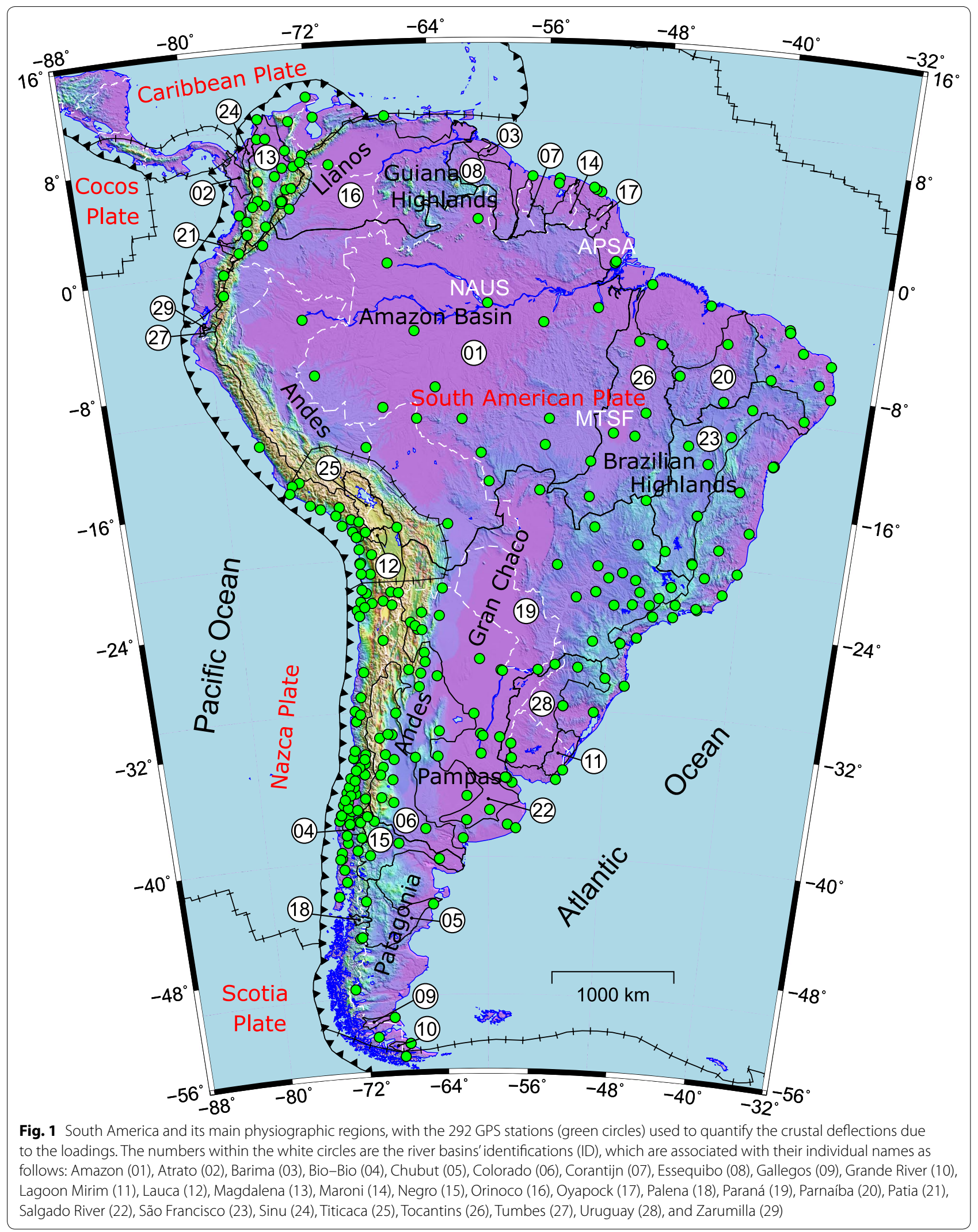


does not provide the degree-one coefficients $\left(C_{1,0}, C_{1,1}\right.$, and $S_{1,1}$, i.e., the reference frame), and the degree-two coefficients $\left(C_{2,0}\right)$ present relatively high uncertainties, we replaced them with those computed by solutions from Swenson et al. (2008) and Sun et al. (2016b), and Cheng and Ries (2017) in their Release 06 version, respectively. Since the nontidal atmospheric and oceanic loadings were not reduced from the GPS time series ("GPS time series" section), we restored these signals removed during the dealiasing process of GRACE solutions. We used Release 06 of GRACE's Atmosphere and Ocean Dealiasing Level-1B (AOD1B) solution (Dobslaw et al. 2017) with the GRACE spherical harmonic solutions to maintain consistency between VCD inferred from GRACE and GPS (given that tidal atmospheric has been reduced from GPS data, see "GPS time series" section). Note that the periodic signals due to the atmospheric tides and their associated oceanic response have been removed using twelve frequencies (the most relevant ones) from AOD1B RL06 (Dobslaw et al. 2017). Consequently, loading deformations due to nontidal atmospheric, ocean, and continental hydrology signals will be present in the GRACE-derived VCDs as computed in the following.

Vertical crustal displacements $(\Delta r)$ due to changing mass loading can be expressed in terms of residual spherical harmonics coefficients of the gravity field and load Love numbers as follows (e.g., van Dam et al. 2007):

$$
\begin{aligned}
\Delta r(\theta, \lambda, t)= & R \sum_{n=1}^{60} \frac{h_{n}^{\prime}}{1+k_{n}^{\prime}} \sum_{m=0}^{n}\left[\Delta C_{n m}(t) \cos m \lambda\right. \\
& \left.+\Delta S_{n m}(t) \sin m \lambda\right] P_{n m}(\cos \theta) .
\end{aligned}
$$

In Eq. (1), $\theta, \lambda$, and $t$ are the colatitude, longitude, and time, respectively; $R$ is the average Earth radius $(6371 \mathrm{~km}), P_{n m}$ are the fully normalized Legendre functions of degree $n$ and order $m ; \Delta C_{n m}$ and $\Delta S_{n m}$ represent the residual of filtered spherical harmonics coefficients (mainly describing variations in the gravity field due to hydrology and nontidal atmospheric and ocean signals) from which the average between 2002 and 2017 was removed. In this study, the convolution-filter coefficients DDK5 (Kusche 2007) were applied to spherical harmonic coefficients (for both geopotential coefficients and AOD1B coefficients) to reduce the contribution of noise at high degrees (cf., Swenson and Wahr 2006). The load Love numbers $h_{n}^{\prime}$ (elastic deformation load Love number) and $k_{n}^{\prime}$ (elastic gravity load Love number) are those defined in a Gutenberg-Bullen (G-B) Earth model provided by Farrell (1972) given in the reference frame of the center of mass of the solid Earth without mass load (CE). To be compatible with the other loading products, the degree-one Love numbers were transformed to the $\mathrm{CF}$ frame as (Blewitt 2003):

$$
\left\{\begin{array}{c}
h_{1}^{\prime} \\
1+k_{1}^{\prime}
\end{array}\right\}_{\mathrm{CF}}=\left\{\begin{array}{c}
2 / 3\left(h_{1}^{\prime}-l_{1}^{\prime}\right) \\
1-1 / 3 h_{1}^{\prime}-2 / 3 l_{1}^{\prime}
\end{array}\right\}_{\mathrm{CE}},
$$

where $l_{n}^{\prime}$ is the degree-one load Love number for the lateral variations due to the mass loading.

Note that Eq. (1) presents the VCDs due to the fluctuations in continental hydrology and the polar ice sheets as well as by (nontidal) changes in atmospheric and oceanic mass distribution. Furthermore, Eq. (1) is developed up to degree and order 96 , so it retains contributions only of the long-wavelength of the vertical deformations. Consequently, the GRACE inverted VCDs lack components with scales of less than approximately $210 \mathrm{~km}$ (at the equator).

\section{Combined loading models (CLMs)}

Continental water storage, atmospheric (nontidal), and nontidal ocean loading are mainly considered in surfaceloading models because these effects are present in the GPS and GRACE datasets as described in "GPS time series and Vertical displacements inverted from GRACE solutions" sections, respectively. However, continental water storage is a dominant source of mass variations at the seasonal timescale (see, e.g., Velicogna et al. 2001; Nahmani et al. 2012). Thus, considering the definition of continental water storage (e.g., Cazenave and Chen 2010) and the availability of the hydrological fields present in the land-surface models, it is assumed that only soil moisture, snow/ice cover, and canopy storage describe the continental water storage. Groundwater storage and surface waters (e.g., lakes and rivers) are usually absent in the most hydrological models due to the scarcity of independent knowledge records. We have appropriately used the loading surface models at the regular $0.25^{\circ} \times 0.25^{\circ}$ global grids provided by the International Mass Loading Service (IMSL, Petrov 2015). The IMSL provides hydrological loading models based on MERRA (Rienecker et al. 2011) and GLDAS-Noah (Rodell et al. 2004). We have used the loading products based on both models since the forcing data and snow models employed by these products vary considerably (cf., Broxton et al. 2016), which impact the amplitudes of modeled VCDs.

The atmospheric-loading deformation is calculated based on the reanalysis numerical weather model MERRA version 2 (MERRA-2, Gelaro et al. 2017) under the inverted-barometer hypothesis (the total pressure variations at the ocean bottom remain constant). Atmospheric-loading fields based on MERRA-2 are recommended for applications that require long-term stability. The loading displacements based on MERRA2 have a horizontal resolution of 2 arc-min $(0.033$ arcdegrees) global grid with a time step of $6 \mathrm{~h}$. The nontidal ocean loading was computed from the Ocean Model for 
Circulation and Tides (OMCT) released by the German Research Centre for the Geosciences (GFZ) (Thomas 2002). Specifically, IMSL provides the loading based on bottom-pressure fields computed with the OMCT05 model (Dobslaw and Thomas 2007), which is represented using the spherical harmonic coefficients. The nontidal ocean loading displacements are on a regular 2 arc-min (0.033 arc-degree) global grid with a time step of $6 \mathrm{~h}$. This series has harmonic variations at diurnal and semidiurnal frequencies removed.

The data were harmonized at the same epoch of those from the space-borne geodetic sensor (GPS and GRACE) solutions through a monthly average. For estimating the seasonal vertical movements from CLMs, we performed the summation of continental water storage, and nontidal atmospheric and ocean effects. We generated two combined models, one including the continental water storage effects of the GLDAS-Noah (hereafter only GLDAS) model and the other including the MERRA-Land (hereafter MERRA) model, which are referred to hereafter as CLM-GLDAS and CLM-MERRA, respectively. Therefore, they are the two CLMs used here to express the modeled VCDs. The time series associated with the surface-loading models are linked to the CF reference frame for a consistent comparison with GPS and GRACE solutions.

\section{Analysis of VCD time series}

To describe the VCD time series, we used the extended linear trajectory model-ELTM (Bevis and Brown 2014), which describes the temporal variations in the ellipsoidal height (also the other components), as well as the trend, acceleration, seasonal oscillations, step functions (abrupt changes arising from earthquakes or equipment changes), and post-seismic signals as:

$$
\begin{aligned}
h(t)= & \sum_{i=1}^{n_{p}+1} p_{i}\left(t-t_{0}\right)^{i-1}+\sum_{j=1}^{n_{J}} b_{j} H\left(t-t_{j}\right) \\
= & +\sum_{k=1}^{n_{F}}\left[s_{k} \sin \left(\omega_{k} t\right)+c_{k} \cos \left(\omega_{k} t\right)\right] \\
& +\sum_{t=1}^{n_{T}} a_{t} \log \left(1+\frac{\Delta t_{t}}{T_{t}}\right) .
\end{aligned}
$$

On the RHS of Eq. (3), the first term is a polynomial trend model in which $n_{p}$ is the order of the polynomial. Here, we used $n_{p}=1$, which provides $p_{1}=h\left(t_{0}\right)$, i.e., the ellipsoidal height in the reference epoch $t_{0}, p_{2}=\dot{h}$ is the velocity, and $t$ is the time in years. The second term on the RHS of Eq. (3) provides the Heaviside function (step function), in which $b_{j}$ characterizes the jump that occurs at time $t_{j}$ as an instantaneous displacement in terms of ellipsoidal height. The Heaviside function is given as

$$
H(t)=\left\{\begin{array}{l}
0 t-t_{j}<0 \\
\frac{1}{2} t-t_{j}=0 . \\
1 t-t_{j}>0
\end{array}\right.
$$

The third term in Eq. (3) shows the model of annual displacement cycle where $n_{F}$ is the number of frequencies and $\omega_{k}=2 \pi / \tau_{k}$, in which $\tau_{1}=1$ year (annual cycle), $\tau_{2}=1 / 2$ year (semiannual cycle), etc. Finally, since some stations are susceptible to post-seismic deformations (western South America), the last term in RHS of Eq. (3) models after slip contributions that generate transient displacements, where $a_{t}$ is the magnitude of the exponential decay due to the post-seismic change in the period $\Delta t_{t}$ in years since the $t$ earthquake event occurred, and the decay time $T$ was configured with default value $T=1$ year, achieving an excellent fit to the data. Note that this model is insensitive to the effect of assigning a moderately erroneous value to the $T$ parameter (cf., Bevis and Brown 2014).

The parameters of the ELTM can be estimated by least-squares adjustment. For most stations used here, it is sufficient to consider $n_{p}=1$ for the polynomial term in Eq. (3) (Bevis and Brown 2014), whereas the hypothesis of sustained accelerations in some stations should be investigated; such investigation would require, $n_{p}=2$, providing $p_{3}=\ddot{h}$ as the acceleration. Furthermore, we applied the full Eq. (3) only to the stations most affected by the Maule earthquake (February 27, 2010, Chile). For the other stations, we applied only the first three terms of the RHS of Eq. (3).

We considered the periodic components of the VCD series by estimating their amplitudes and phases using weighted least squares via the functional model represented by Eq. (3). Specifically, we estimated the annual and semiannual amplitudes and their respective phases of GPS height residuals, GRACE, and CLMs radial displacements. Note that during the study period, the leastsquare fit identified many jumps caused by antenna changes (15 jumps) or earthquakes (52 jumps), which were then corrected from the GPS time series. We computed the Lomb-Scargle periodogram (Horne and Baliunas 1986) for each GPS time series and stored the five most representative (characteristic) frequencies for each time series. This analysis (not presented here) revealed that the annual components are the most representative, and semiannual components have considerably weaker amplitudes than the annual components. 


\section{Consistency analysis of different loading products}

To evaluate the consistency of the GRACE, CLMGLDAS, and CLM-MERRA time series concerning the GPS solutions, we used the reduction in the root-meansquare (RMS). Note that we did not use the weighted RMS (WRMS, van Dam et al. 2007) because the uncertainties for CLMs are not available, and those for GRACE are generally the formal errors as provided for the spherical harmonic coefficients. The percentage of RMS reduction $\left(\mathrm{RMS}_{\text {red }}\right)$ reflecting the degree of agreement between GPS and "modeled" (i.e., GRACE or CLMs) was estimated as:

$$
\begin{aligned}
\operatorname{RMS}_{\text {red }}(\%)= & \frac{\operatorname{RMS}\left(\Delta h_{i}^{\mathrm{GPS}}\right)-\operatorname{RMS}\left(\Delta h_{i}^{\mathrm{GPS}}-\Delta r_{i}^{\mathrm{mod}}\right)}{\operatorname{RMS}\left(\Delta h_{i}^{\mathrm{GPS}}\right)} \\
& \times 100,
\end{aligned}
$$

where RMS $\left(\Delta h_{i}^{\mathrm{GPS}}\right)$ is the signal RMS for GPS, and RMS $\left(\Delta h_{i}^{\mathrm{GPS}}-\Delta r_{i}^{\mathrm{mod}}\right)$ is the signal RMS of the GPSGRACE residuals or the signal RMS of the GPS-CLMs (i.e., "mod" stands for CLM-GLDAS or CLM-MERRA) residuals. Larger positive RMS reduction values indicate better agreement between model-based VCD and GPSVCD. Conversely, larger negative RMS reduction values indicate worse agreement. For sites for which the RMS reduction values are negative, the agreements between GPS and other data sources are generally weak. It is noteworthy that in Eq. (5) we have considered $\Delta h \approx \Delta r$, that is, the variations in ellipsoidal height $(\Delta h)$ approximate the variations in the radial displacement $(\Delta r)$, since in an extreme case the relative difference is less than $\Delta h\left(5.6 \cdot 10^{-6}\right)$; that is, it is negligible (Ferreira et al. 2018).

\section{Results}

\section{Consistency analysis of the different loading products}

Figure 2 shows the displacements observed at the NAUS station located in the Amazon Basin (ID 01 in Fig. 1), specifically at the confluence of the Solimões (the upper Amazon River) and the Negro at the Brazilian city of Manaus (the NAUS site is identified in Fig. 1). Figure 2 additionally shows the VCDs derived from GRACE and predicted by the CLMs. An annual signal was clearly visible in the observed as well as the loading derived from GRACE and CLMs. It seemed that the GRACE signal was in phase and has the closest amplitude, as did those from the GPS displacements. However, for the CLMs considering GLDAS and MERRA, there seemed to have an overall underestimation of the amplitude; this might be due to the missing water storage components in the hydrological models (e.g., surface and ground water storages). The RMS reductions were $69.9 \%, 17.4 \%$, and $17.0 \%$ for GRACE, CLM-MERRA, and CLM-GLDAS, respectively.

Further, Fig. 2 also presents the series of the VCDs at the MTSF (Tocantins Basin, ID 26 in Fig. 1) and APSA

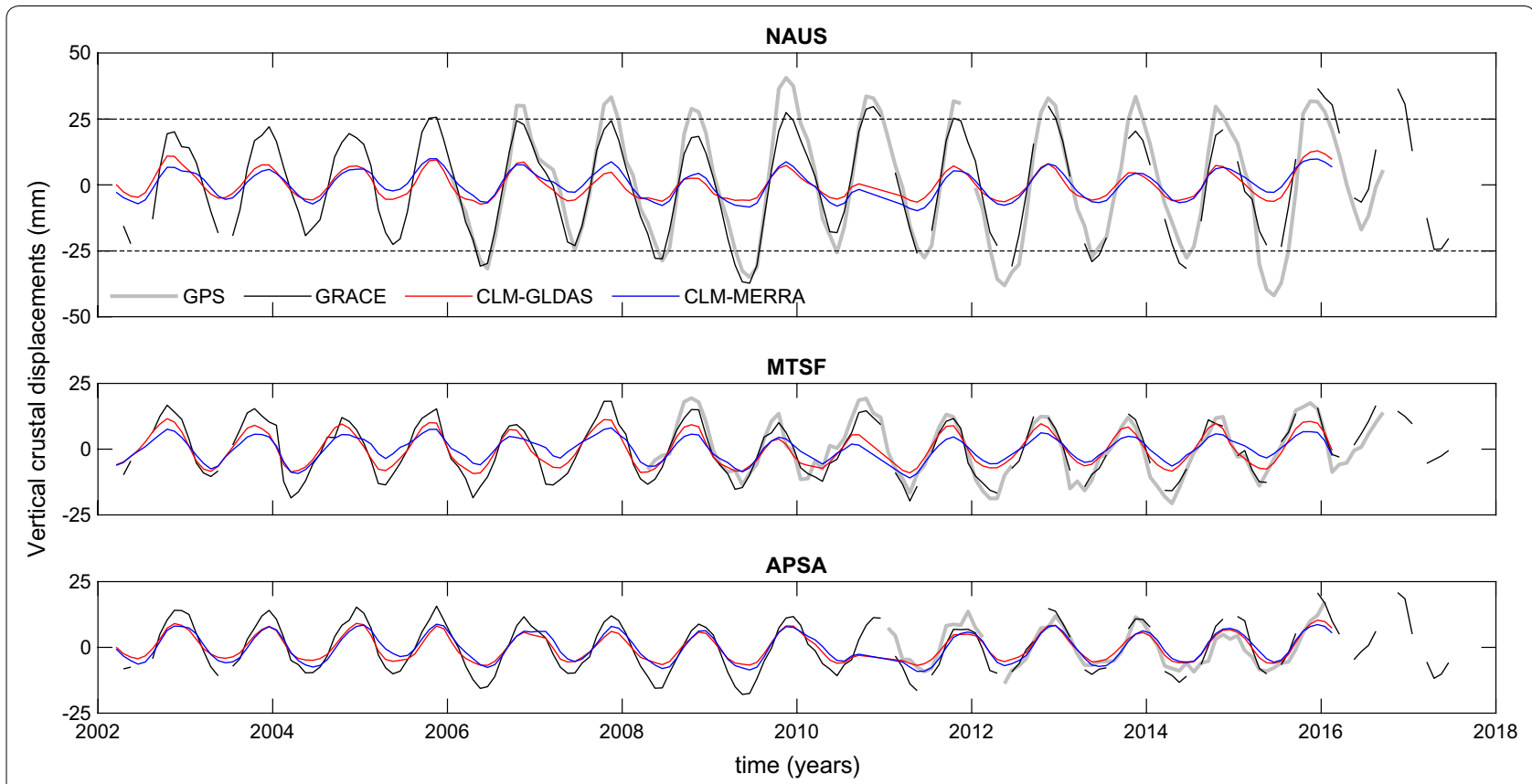

Fig. 2 Vertical crustal displacements at NAUS, MTSF, and APSA stations, Brazil, observed from GPS and predicted from GRACE, and CLM-GLDAS and CLM-MERRA. The three stations are identified in Fig. 1 
(South Atlantic, at the Amazon River Estuary) stations (both are indicated in Fig. 1). The overall RMS reductions for the variability at MTSF were $71.7 \%, 47.2 \%$, and 30.6\% for GRACE, CLM-GLDAS, and CLM-MERRA, respectively. Again, CLMs underestimated the overall amplitudes of the VCDs, whereas a slight improvement for NAUS stations was observed. The APSA site presented the best reduction in the RMS of the VCDs considering CLM-MERRA (61.5\%) and CLM-GLDAS (60.1\%), whereas the reduction considering GRACE still showed some improvement (33.9\%). A sound agreement was noted between GPS-observed VCDs and those derived from GRACE and the CLMs regarding the correlation coefficients (CCs) for the three stations shown in Fig. 2. For example, NAUS presented 1.0 for GPS vs GRACE, 0.9 for GPS vs CLM-GLDAS, and 0.8 for GPS vs CLM-MERRA; these figures were 1.0, 0.9, and 0.8 at MTSF, and 0.9, 0.9, and 0.9 at APSA, respectively. To summarize the results for the 292 GPS sites, Fig. 3 (top panels) shows the correlation coefficients at zero phase lags of GRACE (Fig. 3a), CLM-GLDAS (Fig. 3b), and CLM-MERRA (Fig. 3c) concerning the GPS series.

The correlation between GPS with GRACE time series revealed that approximately $45 \%$ (131 stations) of the stations had correlation coefficients higher than 0.6. The correlation values higher than 0.6 passed Student's $t$ test with a significance level of $5 \%$, while only $4 \%$ of the 292 stations failed. These stations presented correlation values that did not exceed \pm 0.1 . Among these 131 stations, 42 showed a good correlation coefficient (0.6-0.7), while the 89 remaining showed a correlation coefficient higher than 0.7. In general, the stations with the highest correlations were in the Magdalena (ID 13), Orinoco (ID 16), Paraná (ID 19), Amazon (ID 01), São Francisco (ID 23), Parnaiba (ID 20), and Tocantins (ID 26) Basins. However, isolated stations in other regions with significant correlation values (e.g., coastal region, $4^{\circ} \mathrm{S}$ to $8^{\circ} \mathrm{N}$ ) could also be observed (see Fig. 3a).

The correlation between the GPS and CLM-GLDAS (Fig. 3b) time series revealed that approximately 43\% (125 stations) of the stations reached a correlation coefficient greater than 0.6. The correlation values greater than 0.6 passed Student's $t$ test with a significance level of 5\%, and in this case as well as GRACE-VCD, only $5 \%$ of the 292 stations did not pass the $t$ test. Correlation coefficient values for these stations did not exceed \pm 0.1 . Moreover, 40 stations showed a good correlation (0.6-0.7), and 85 stations showed a higher correlation $(>0.7)$. Concerning the spatial distribution of the stations with better correlations than 0.6, no pattern was apparent with distribution throughout the entire continent (see Fig. 3b). Almost the same pattern occurs between GPS and CLM-MERRA; approximately $41 \%$ (121) of the stations reached a correlation coefficient greater than 0.6 , and 82 of these were higher than 0.7 .

The GPS and CLM-MERRA correlation values greater than 0.6 passed the $t$ test with a significance level of $5 \%$, and only $4 \%$ of the 292 stations did not pass the $t$ test; these stations showed correlation coefficient values that did not exceed \pm 0.1 . Note that this was not surprising, as both time series (CLM-GLDAS and CLM-MERRA) were highly coincident over most places, excluding the Paraná River Basin (ID 19), northern Chile and Argentina, and from $16^{\circ} \mathrm{S}$ to $5^{\circ} \mathrm{N}$ along the Peruvian coast and the Ecuadorian Andes.

Figure 3 (bottom panels) also shows the percentage reduction concerning RMS values when VCDs derived from GRACE (Fig. 3d), CLM-GLDAS (Fig. 3e), and CLM-MERRA (Fig. 3f) were considered in the GPS-VCD series as per Eq. (5).

When we applied the reduction of GPS series with GRACE data for the 292 GPS sites across South America (Fig. 3d), we found 201 sites with positive RMS reduction values. Many of these positive RMS reductions values (163 of 202 sites) were in the range of 0 to $40 \%$. The negative values (91 sites) were mainly in the range of -20 to $0 \%$ ( 74 of 91 sites), which were smaller than the positive values. The spatial distribution of the stations with positive RMS reduction values was homogeneous throughout the South American continent. However, the higher values $\left(\mathrm{RMS}_{\text {red }}>30 \%\right)$ were concentrated in the Amazon (ID 01), Tocantins (ID 26), Paraná (ID 19), São Francisco (ID 23), Paranaiba (ID 20), and Uruguay (ID 28) Basins. On the other hand, a set of stations ( 50 stations) with negative RMS reductions values were concentrated in the coastal region of northern Chile and southern Peru (see Fig. 3d).

However, when we applied the reduction in GPS series considering the values of CLM-GLDAS (Fig. 3e), we found 214 sites with positive RMS reduction values. Among the 214 stations that achieved positive RMS reduction values, 197 stations were between 0 and $40 \%$, and 54 of 78 stations with negative values were between 0 and $-20 \%$ (see Fig. 3e).

When we reduced the GPS series with the CLMMERRA time series (Fig. 3f), we found 222 stations with positive RMS reduction values, of which 175 stations presented values between 0 and 30\% positive RMS reduction and of the 70 stations with negative RMS reduction values, 50 had values between 0 and $-20 \%$ (see Fig. 3f).

In the case of the RMS reductions values for CLMGLDAS and CLM-MERRA, the spatial distribution of the stations with positive RMS reduction values was homogeneous throughout the South America continent, and negative RMS reduction values were sparsely distributed. 


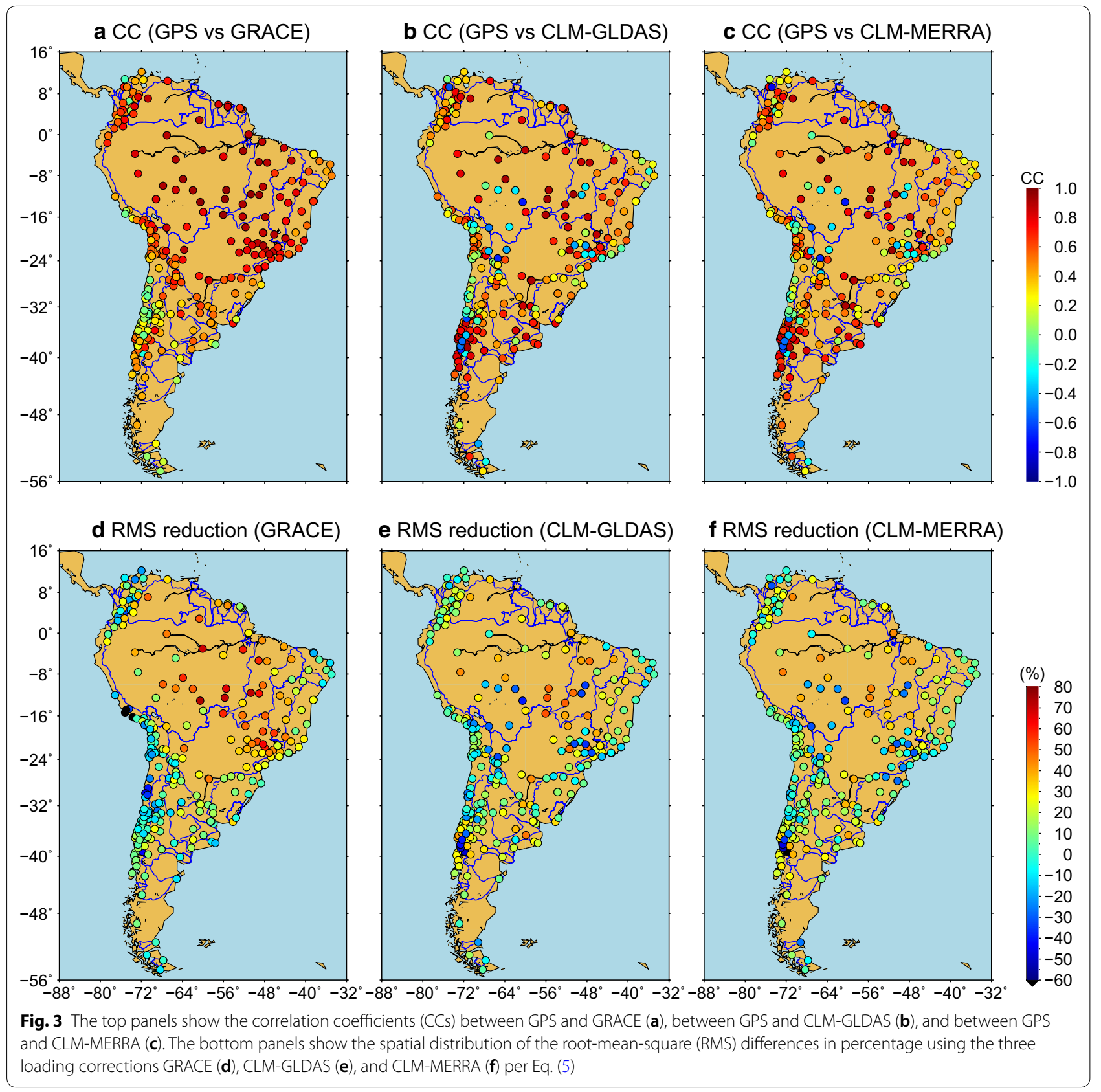

Overall, the stations that presented the highest performance regarding positive RMS values were located between latitudes higher than $16^{\circ} \mathrm{S}$ and longitudes greater than $67^{\circ} \mathrm{W}$ (east of $-67^{\circ}$ ); that is, the 187 GPS sites were located mainly in the Amazon Rainforest and Brazilian Highlands. Table 1 summarizes the results considering all stations (292 stations) and those placed around the Amazon Rainforest and Brazilian Highlands (187 sites).
The best performance concerning the mean of the RMS reduction values was found for the GRACE time series (28.5\%), followed by CLM-GLDAS (22.4\%) CLMMERRA and (21.5\%) as shown in Table 1 . This was also the case for correlations; the GRACE time series produced the best values (113 of 187 stations with correlations greater than 0.6 with a mean value of 0.78 ), followed by CLM-GLDAS ( 80 of 187 stations with correlations greater than 0.6 with a mean value of 0.76 ). The 
Table 1 Summary of the reduction in the root-meansquare $\left(\mathbf{R M S}_{\text {red }}\right)$ and correlation coefficient (CC) values for all stations (292 sites) and for those selected after removing stations with latitudes less than $16^{\circ} \mathrm{S}$ and longitudes east of $67^{\circ} \mathrm{W}$ ( 187 sites)

\begin{tabular}{|c|c|c|c|c|}
\hline \multirow[t]{2}{*}{ Source } & \multicolumn{2}{|c|}{ All stations (292) } & \multicolumn{2}{|l|}{187 stations } \\
\hline & $\mathrm{RMS}_{\text {red }}$ & $\mathrm{CC}>0.6$ & $\mathrm{RMS}_{\text {red }}$ & $C C>0.6$ \\
\hline GPS/GRACE & $201(24.0 \%)$ & $131(0.77)$ & $148(28.5 \%)$ & $113(0.78)$ \\
\hline GPS/CLM-GLDAS & $214(21.6 \%)$ & $125(0.76)$ & 137 (22.4\%) & $80(0.76)$ \\
\hline GPS/CLM-MERRA & $222(20.5 \%)$ & $121(0.75)$ & 141 (21.5\%) & $75(0.75)$ \\
\hline
\end{tabular}

However, only stations with reduction in the RMS (RMS red $>0 \%)$ and CC values larger than 0.60 were used to summarize the mean values (in parentheses)

worst series was that of CLM-MERRA (75 of 187 stations with correlations greater than 0.6 with a mean value of $0.75)$. On the other hand, the stations that presented the worse performances regarding RMS reduction values for GRACE, CLM-GLDAS, and CLM-MERRA were concentrated in Colombia, on the coast of Brazil, and the coast in the north of Chile and south of Peru.

\section{Characterization of seasonal displacements at the GPS sites}

The results for annual components based on Eq. (3) are shown in Fig. 4. According to the results obtained from the GPS series (Fig. 4a), the most significant annual amplitudes (twice the mean annual amplitude, i.e., $>10 \mathrm{~mm}$ ) were mainly concentrated north of parallel $20^{\circ} \mathrm{S}$, that is, in basins of the Amazon River (basin ID 01 in Fig. 1) and Tocantins River (basin ID 26 in Fig. 1).

In the case of the annual vertical deformations obtained from the inversion of the GRACE spherical harmonic coefficients using Eq. (1), the results showed that the most substantial annual amplitudes $(>8 \mathrm{~mm})$ are also identified in the Amazon (ID 01), Tocantins (ID 26), Paraná (ID 19), and Paranaiba (ID 20) River Basins (see Fig. 4b). In the case of CLM-GLDAS (see Fig. 4c), larger annual amplitudes $(>5 \mathrm{~mm}$ ) were found in the eastern Amazon (ID 01), Tocantins (ID 26), Parnaiba (ID 20), and only two stations located in the Paraná (ID 19) River Basin. For the CLM-MERRA (see Fig. 4d), the annual deformations reached the highest values $(>5 \mathrm{~mm})$ predominantly in the basins of Amazon River (ID 01) and Tocantins River (ID 26), and scattered stations in the Parnaiba River (ID 20), two stations, and Paraná River (ID 19), three stations.

In general, for the CLM-GLDAS (Fig. 4c) and CLMMERRA (Fig. 4d) models, the stations located in the physiographic region of Amazon Rainforest and Brazilian Highlands presented the large annual seasonal variations of VCDs and reached values up to $10 \mathrm{~mm}$ (Fig. 4c, $\mathrm{d}$, respectively). These regions of South America are characterized by annual total rainfalls up to $3000 \mathrm{~mm}$ and $1600 \mathrm{~mm}$, respectively; the former is located mainly in the Intertropical Convergence Zone (ITCZ), which is characterized by heavy rainfall over the Amazon Rainforest.

It should be noted that GPS and GRACE time series revealed that the station that reached the most significant annual amplitude was located in the central Amazon Basin (Manaus); CLM-GLDAS and CLM-MERRA reveal two stations located in the Amazon Basin. The maximum annual amplitude values of VCDs were those observed at the Manaus (central Amazon Basin) site, which reached 30, 24, 9, and $8 \mathrm{~mm}$, for GPS, GRACE, CLM-GLDAS, and CLM-MERRA, respectively.

Overall, the mean values for annual amplitudes of the VCDs for GPS, GRACE, CLM-GLDAS, and CLMMERRA are 5.2, 4.4, 2.5, and $2.4 \mathrm{~mm}$, respectively. Thus, in general, the annual VCDs in South America recovered by the monthly GRACE solutions reached $85 \%$ of the GPS signal. In the case of CLM-GLDAS and CLM-MERRA, they reached only $48 \%$ and $46 \%$, respectively. However, in a detailed analysis of the data, GPS and GRACE coincided more closely when the amplitudes were larger, north of $20^{\circ} \mathrm{S}$. Greater disagreement occurred over southern South America, south of $30^{\circ} \mathrm{S}$, and along the western South American coast. This was also the case for the behavior of annual phases (direction of the arrows). However, depending on the locations of the GPS stations throughout Chile, Peru, Ecuador, Colombia, and Venezuela, the results varied greatly (phase shift values between GPS and GRACE are not shown). Of note, there was generally little agreement between the phases of GPS and GRACE in these locations.

\section{Discussion}

One main goal of our experiment was to understand the role that lateral transfer of masses due to the coupled contributions of nontidal atmospheric, oceanic, and hydrological mass variations play on GPS stations spread over South America. Thus, we compiled a database with 292 GPS stations suitable for studies of the crustal deformations (Fig. 1). The variability was investigated over South America considering its physiographic regions and the main river basins. Understanding the contribution of mass loadings on the stations that compose the SIRGAS is essential for consistent maintenance of this regional reference system as local densification of the ITRF (Sánchez and Drewes 2016). Hence, our study was the first attempt to investigate VCD's variabilities throughout the whole continent over approximately 15 years (2002 through 2016) for many stations. 


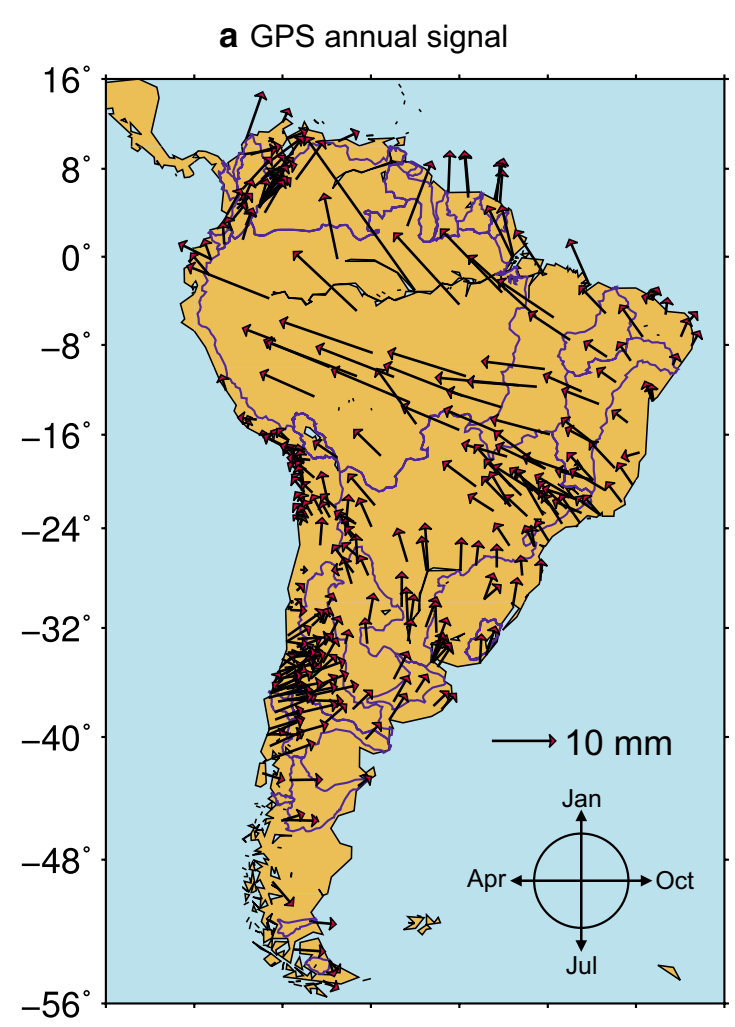

c CLM-GLDAS annual signal

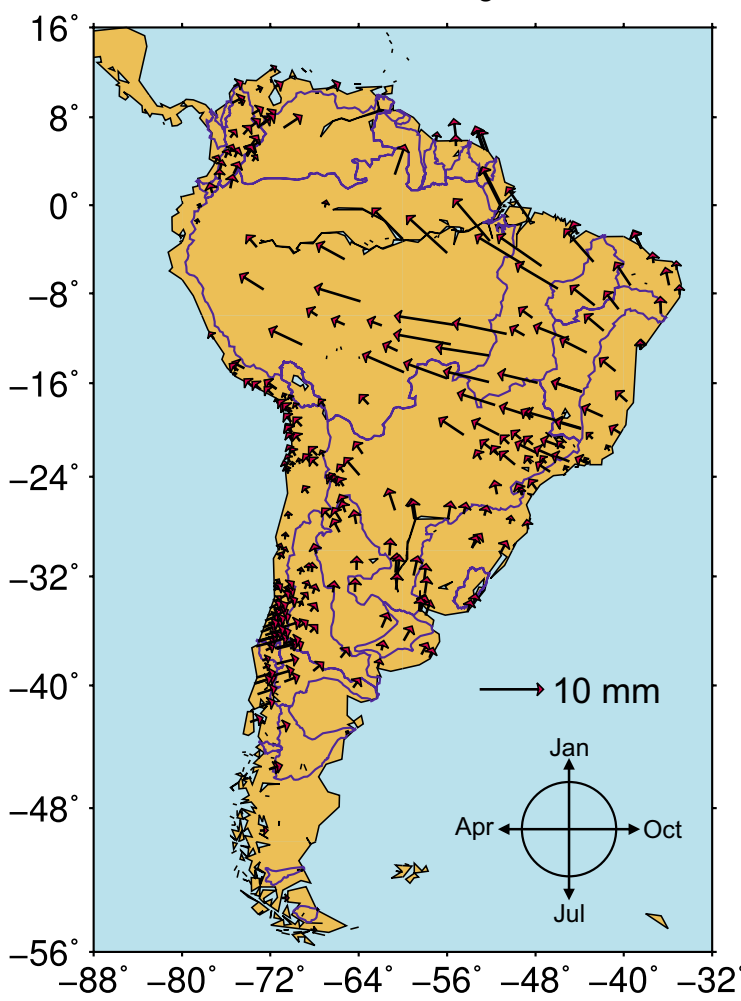

b GRACE annual signal

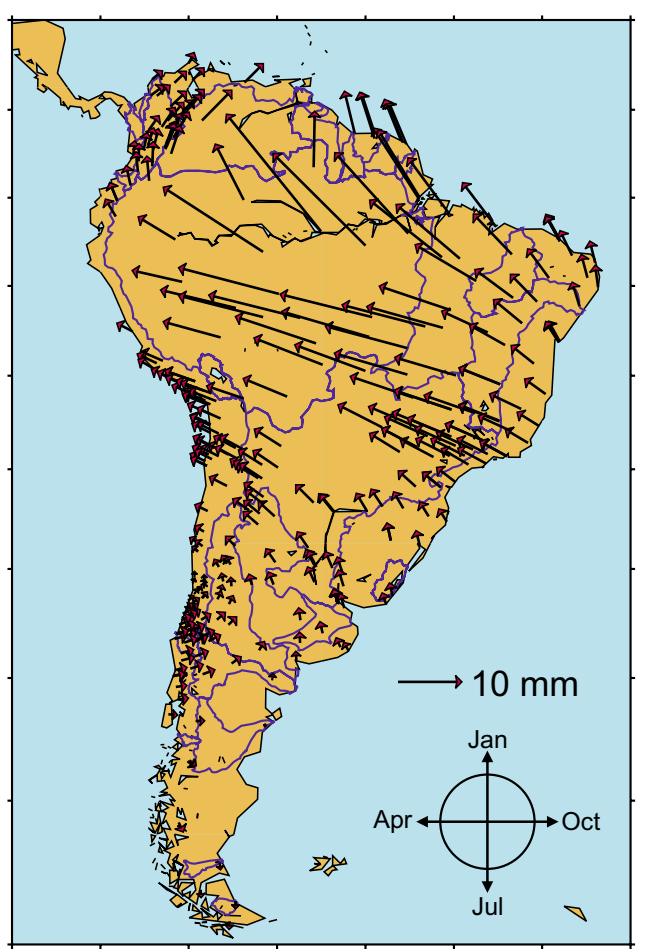

d CLM-MERRA annual signal

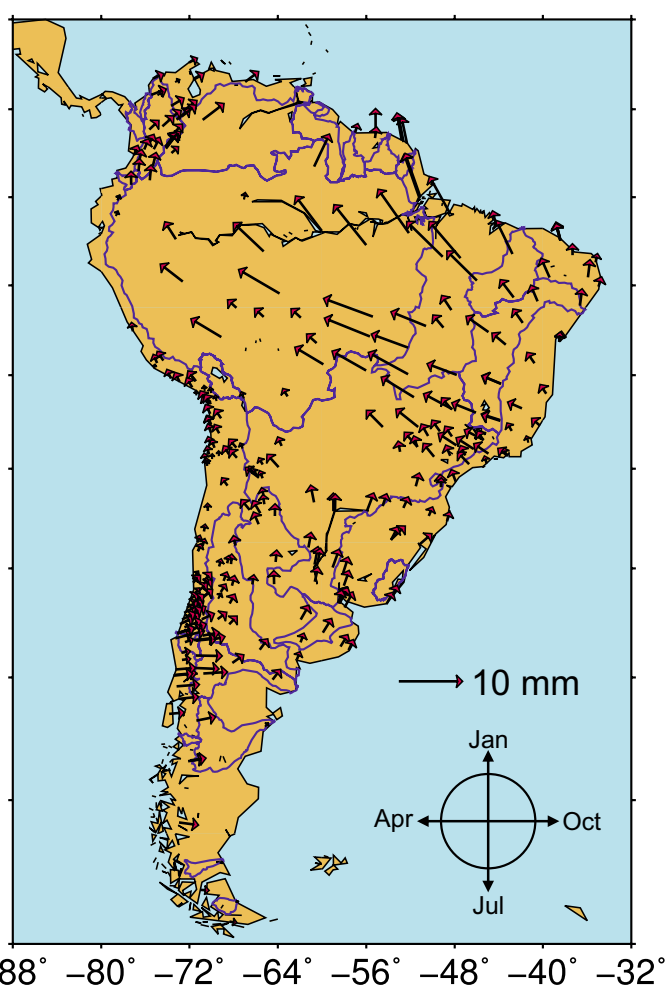

Fig. 4 Annual amplitudes and phases of $\mathbf{a}$ GPS height residuals, $\mathbf{b}$ GRACE inverted VCDs, c CLM-GLDAS modeled VCDs, and $\mathbf{d}$ CLM-MERRA modeled VCDs. The lengths of the arrows represent the annual amplitudes of the deformations in $\mathrm{mm}$, and the directions present the phases where the peak values of the loadings are counted counterclockwise from the north (January) 
Previous studies, for example Moreira et al. (2016), have reported VCDs up to $10 \mathrm{~cm}$ (based on model) in the Amazon River, which shows the importance of the hydrology of the basin on the GPS networks dedicated to geodynamic studies. In this regard, we analyzed the characteristics of the annual VCD derived from GRACE, CLM-GLDAS, and CLM-MERRA time series (Fig. 4). Overall, at the annual time scale, the VCD captured by GPS, GRACE, and CLMs showed consistency, and interestingly, there is a correlation with the physiographic provinces. For the GPS time series (Fig. 4a), we found that the highest amplitudes of annual vertical deformations are concentrated in the Amazon and Tocantins River Basins. This is further emphasized by Fig. $5 \mathrm{a}$, which depicts the summary of Fig. 4, that is, the zonal distributions of the annual amplitudes for GPS, GRACE, CLMGLDAS, and CLM-MERRA.
For the GRACE time series, these occur at the Amazon, Tocantins, Paraná, and Parnaiba River Basins (Fig. 4b). Likewise, for the CLM-GLDAS and CLM-MERRA time series, the most considerable annual vertical deformations occurred in the eastern Amazon, Tocantins, Parnaiba, and scarcely in the Paraná River Basins (Fig. 4c, d). Specifically, over those basins, the variability of the stations located therein mainly reflects the hydrological loadings. It was evident that seasonal signals due to the atmospheric loading appear in most stations, apart from the western coastal region of South America, which comprises the Andes Mountains. Furthermore, the influence of nontidal ocean mass distribution reached approximately $0.4 \mathrm{~mm}$ for only $4 \%$ of the stations in South America, and the impact for inland stations is less than $0.3 \mathrm{~mm}$, which is negligible compared with the atmospheric and hydrological loadings.

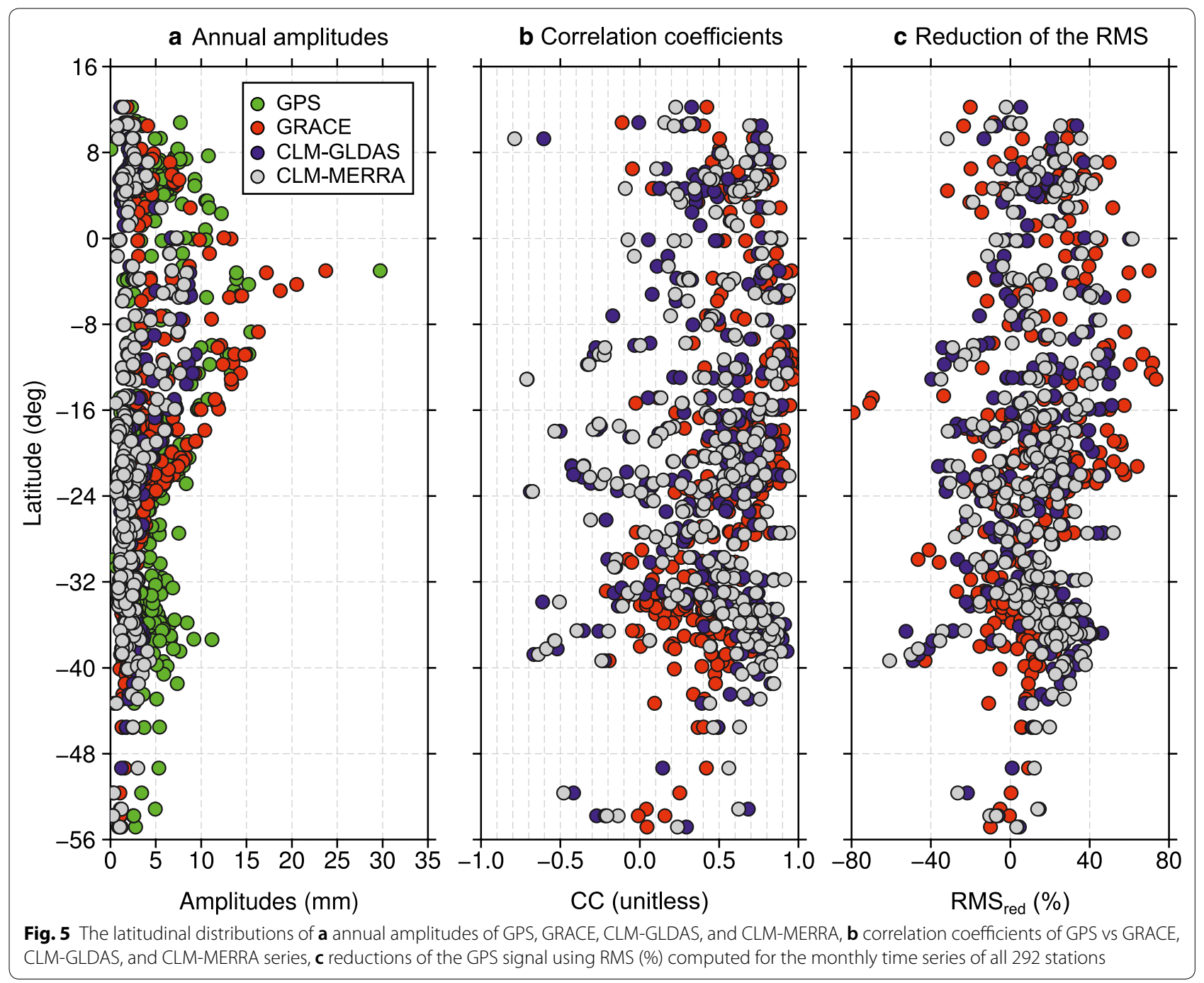


However, as can be observed from Fig. 5a, our results show that GPS depicted relatively large amplitudes in the regions encompassed by the latitude bands of $-40^{\circ}$ to $-30^{\circ}$. Nevertheless, the amplitudes shown by GRACE, CLM-GLDAS, and CLM-MERRA reached up to half of those from GPS (Fig. 5a). Regarding the CLMs and the performance of the GLDAS and MERRA, it is well known that they poorly represent other sources of loading, especially their distributions (soil moisture, groundwater, snow, and ice). It is noteworthy that those residual mass distributions are scarcely observed in most regions of the globe, and their induced residual deformations are significant enough to be found in the GPS series. GRACE in its turn is influenced by errors in the monthly fieldsolution estimates, small-scale features in the load field not captured, and leakage problems. The GPS stations are highly sensitive to local loading effects and to isolated stations with large annual amplitudes such as those shown in Fig. 5a over Chile (also Fig. 4a). For example, in the case of a station located at southwestern Chile (LAJA), we found the annual amplitude of VCD up to $11.2 \mathrm{~mm}$ based on GPS. This variation is associated with fluctuations dominated by the Earth's local elastic response to the changing weight of water in the Laja Reservoir (Bevis et al. 2004). Of course, this local signal could not properly be recovered by the other datasets used here (compare the annual amplitudes in Fig. 5a).

Excluding this region of Chile from our analysis, we found a good correlation on the agreement between GPS and GRACE data with the other physiographic provinces of South America (Table 1 and Fig. 5b). Furthermore, with the exception of south of $16^{\circ} \mathrm{S}$ and west of $67^{\circ} \mathrm{W}$ (along the southern Andes), that is, for 187 GPS sites, the greatest RMS reductions in GPS series are reached while using the GRACE time series $(79 \%$ of the 187 sites), followed by CLM-MERRA (75\% of the 187 sites) and CLM-GLDAS (74\% of the 187 sites), as can be observed in Fig. 5c and Table 1. Regarding the correlation coefficient, GRACE time series reached the best values (113 of 187 stations with correlations greater than 0.6), followed by CLM-GLDAS (80 of 187 stations with correlations greater than 0.6), and the worst series were those of CLM-MERRA (75 of 187 stations with correlations greater than 0.6). However, at these sites, the excellent agreement between GPS and GRACE data at the annual time scale are not matched by the data from hydrological models (Fig. 5a), which account for only half of the amplitudes detected by the space-borne geodetic sensors (GPS and GRACE).

The agreement of the models is the reason why in all 292 GPS sites throughout the whole of South America, the most successful source regarding RMS reduction values was CLM-MERRA (76\% of the 292 sites), followed closely by CLM-GLDAS (73\% of the 292 sites), and the worst performance was obtained by the GRACE (69\% of the 292 sites) time series (see Table 1 and Fig. 5c). However, considering all 292 stations with correlation coefficients greater than 0.6, GRACE presented the best results (131 stations) followed by CLMGLDAS (125 stations), and the worst performance was associated with CLM-MERRA model (121 stations), which is related to good performances at stations located in the Amazon Rainforest and Brazilian Highlands (Fig. 3a-c).

More than 100 stations used here (a total of 292 GPS stations) are in a region associated with very active tectonic interaction between the Nazca and South American plates (Fig. 1). In this region, the loading effects due to the dynamics of the artificial reservoirs (e.g., Lake Laja) are significant and not present in the global solutions (Fig. 5a, approx. latitude $37.39^{\circ} \mathrm{S}$ ). Apparently, the CLM-GLDAS and CLM-MERRA do not present the contributions of the reservoirs, and the lack of in situ observations over these regions might compromise the performance of the models in reducing the variability observed by the GPS. This could be the fundamental cause of disagreement in the GPS time series concerning the series of GRACE and CLMs in the southwest region of South America, and it deserves further investigation. Thus, prospective studies using the database generated here will allow other investigations to elucidate these differences much more clearly. (For example, on the west side of South America, on either side of the Andes, where evidently tectonics plays a crucial role.) Further study will better elucidate what happens at sites located to the east, where hydrological models do not manage to predict what is shown by the GPS-VCDs correctly (Fig. 5a). To this end, poroelastic effects due to the lowering of groundwater aquifers (e.g., Tan et al. 2016) do not seem to be apparent in the GPS-VCDs over South America (Ferreira et al. 2019). However, few stations demonstrate significant anti-correlation with significant amplitudes, which could indicate phase lags between those displacements observed by GPS and those derived from GRACE and CLMs. These deserve further investigation, although there seems to be no area of heavy groundwater abstraction in the continent (e.g., Campuzano et al. 2014).

\section{Conclusions}

In this study, we analyzed VCDs due to surface mass loadings (atmospheric, oceanic, and hydrological masses) using data from GPS, GRACE, and data derived from combined models (CLM-GLDAS and CLM-MERRA), over the main physiographic provinces of South America. It is important to maintain and update reference systems 
such as the SIRGAS, which is a regional densification of the ITRF. In this regard, all known time-variable signals must be reduced from the GPS observations (or another space geodesy technique). Thus, our findings suggest: (i) The reduction in the variability of the GPS ellipsoidal height is possible with GRACE-derived radial displacement, which explains approximately $79 \%$ of these variations. This is followed by CLM-MERRA with $75 \%$, and CLM-GLDAS with $74 \%$. However, these results were possible only for stations located in the physiographic provinces of Amazon Basin and Brazilian Highlands, where the major river basins such as the Amazon and Tocantins are located. If all 292 GPS stations are considered, these figures change to $69 \%, 73 \%$, and $76 \%$, for GRACE, CLM-GLDAS, and CLM-MERRA, respectively. This indicates that the mass radial displacements inverted from GRACE data are consistent with GPS only for large basins, and there are relatively strong seasonal variations. (ii) For southwest South America, specifically over Chile, there are strong seasonal variations of VCDs in the GPS series that are not presented in the GRACE monthly solutions. Furthermore, the two loading models (CLM-GLDAS and CLM-MERRA) explained only up to $50 \%$ of the amplitudes detected by GPS over this region. Thus, models and GRACE-derived VCDs should be used with caution to remove seasonal signals in the GPS observations to extract other signals over South America. In addition, specifically over Chile, one must consider the contributions of surface reservoirs such as Laja, Pangue, Ralco, and Angostura. Further work will concentrate on building a local hydrological model by assimilating surface water compartments, which might help improve the results.

\begin{abstract}
Abbreviations
AOD1B: Atmosphere and Ocean Dealiasing Level-1B; CE: center of the mass of the solid earth; CF: center of figure; CLMs: combined loading models; CM: center of mass of the total Earth system; CSR: Center for Space Research, the University of Texas at Austin; ELTM: extended linear trajectory model; G-B: Guttenberg-Bullen; GFZ: Germany Research Centre for Geosciences; GLDAS: Global Land Data Assimilation Systems; GPS: Global Positioning System; GRACE: Gravity Recovery and Climate Experiment; IERS: International Earth Rotation and Reference Systems Service; IGS: International Global Navigation Satellite Systems Service; IMSL: International Mass Loading Service; ITCZ: Intertropical Convergence Zone; ITRF: International Terrestrial Reference Frame; JPL: Jet Propulsion Laboratory; MERRA: Modern-Era Retrospective Analysis for Research and Applications; NGL: Nevada Geodetic Laboratory; OMCT: Ocean Model for Circulation and Tides; SLR: satellite laser ranging; SIRGAS: South American Geocentric Reference System; VCD: vertical crustal deformation.
\end{abstract}

\section{Acknowledgements}

VGF acknowledges the support from the National Natural Science Foundation of China (Grant No. 41574001) and Fundamental Research Funds for the Central Universities (Grant No. 2018B18114). HDM would like to thank the Ph.D. scholarship granted by the University of Concepción (UdeC). SRCF thanks CNPq (Grant process No. 306936/2015-1) and the Federal University of Paraná for the Senior Professor fellowship. The authors thank the CSR center for providing monthly solutions of the gravitational field, the International
Mass Loading Service (IMLS) for providing the surface-loading models data, the S1 and S2 Atmospheric Tide Loading Calculator for providing the atmospheric tidal constituents, and the Nevada Geodetic Laboratory (NGL) at the University of Nevada, Reno for providing the GPS time series. We also would like to express our gratitude to the reviewers and the Vice Editor-in-Chief Prof. Masato Furuya for the valuable comments and suggestions.

\section{Authors' contributions}

VGF and HDM conceived of the idea and designed the experiments. HDM collected the data and conducted the experiments. VGF drafted the first version of the manuscript. All authors contributed to the analysis and discussions of the results and contributed to the final version of the manuscript. All authors read and approved the final manuscript.

\section{Funding}

This work was partially supported by the National Natural Science Foundation of China (NSFC) through Grant Number 41574001.

\section{Availability of data and materials}

All datasets used herein are freely available online on the web.

\section{Ethics approval and consent to participate}

Not applicable.

\section{Consent for publication}

Not applicable.

\section{Competing interests}

The authors declare that they have no competing interests.

\author{
Author details \\ ${ }^{1}$ School of Earth Sciences and Engineering, Hohai University, Nanjing, \\ China. ${ }^{2}$ Departamento de Ciencias Geodésicas y Geomática, Universidad de \\ Concepción, Los Angeles, Chile. ${ }^{3}$ Australian Rivers Institute and Griffith School \\ of Environment \& Science, Griffith University, Nathan, QLD 4111, Australia. \\ ${ }^{4}$ Department of Geophysics, University of Concepción, Concepción, Chile. \\ ${ }^{5}$ Geodetic Sciences Graduation Course, Federal University of Paraná, Curitiba, \\ Brazil.
}

Received: 23 December 2018 Accepted: 23 July 2019

Published online: 01 August 2019

\section{References}

Altamimi Z, Collilieux X, Métivier L (2011) ITRF2008: an improved solution of the international terrestrial reference frame. J Geod 85:457-473. https:// doi.org/10.1007/s00190-011-0444-4

Bar-Sever YE, Kroger PM, Borjesson JA (1998) Estimating horizontal gradients of tropospheric path delay with a single GPS receiver. J Geophys Res 103:5019. https://doi.org/10.1029/97JB03534

Bertiger W, Desai SD, Haines B et al (2010) Single receiver phase ambiguity resolution with GPS data. J Geod 84:327-337. https://doi.org/10.1007/ s00190-010-0371-9

Bevis M, Brown A (2014) Trajectory models and reference frames for crustal motion geodesy. J Geod 88:283-311. https://doi.org/10.1007/s0019 0-013-0685-5

Bevis M, Kendrick E, Cser A, Smalley R (2004) Geodetic measurement of the local elastic response to the changing mass of water in Lago Laja, Chile. Phys Earth Planet Inter 141:71-78. https://doi.org/10.1016/j. pepi.2003.05.001

Bevis M, Alsdorf D, Kendrick E et al (2005) Seasonal fluctuations in the mass of the Amazon River system and Earth's elastic response. Geophys Res Lett 32:1-4. https://doi.org/10.1029/2005GL023491

Blewitt G (1989) Carrier phase ambiguity resolution for the Global Positioning System applied to geodetic baselines up to $2000 \mathrm{~km}$. J Geophys Res 94:10187-10203. https://doi.org/10.1029/JB094iB08p10187

Blewitt G (2003) Self-consistency in reference frames, geocenter definition, and surface loading of the solid Earth. J Geophys Res. https://doi. org/10.1029/2002jb002082 
Blewitt G, Hammond W, Kreemer C (2018) Harnessing the GPS Data Explosion for Interdisciplinary Science. Eos (Washington DC). https://doi. org/10.1029/2018eo 104623

Boehm J, Niell A, Tregoning P, Schuh H (2006) Global Mapping Function (GMF): a new empirical mapping function based on numerical weather model data. Geophys Res Lett. https://doi.org/10.1029/2005gl025546

Broxton PD, Zeng X, Dawson N (2016) Why do global reanalyses and land data assimilation products underestimate snow water equivalent? J Hydrometeorol 17:2743-2761. https://doi.org/10.1175/JHM-D-16-0056.1

Buytaert W, Breuer L (2013) Water resources in South America: sources and supply, pollutants and perspectives. Underst Freshw Qual Probl a Chang World 361:106-113

Campuzano C, Hansen AM, De Stefano L et al (2014) Water resources assessment. In: Willaarts BA, Garrido A, Llamas MR (eds) Water for food and wellbeing in Latin America and the Caribbean. Social and Environmental Implications for a Globalized Economy, New York, pp 27-53

Cazenave A, Chen J (2010) Time-variable gravity from space and present-day mass redistribution in the Earth system. Earth Planet Sci Lett 298:263-274. https://doi.org/10.1016/j.epsl.2010.07.035

Chanard K, Avouac JP, Ramillien G, Genrich J (2014) Modeling deformation induced by seasonal variations of continental water in the Himalaya region: sensitivity to Earth elastic structure. J Geophys Res Solid Earth 119:5097-5113. https://doi.org/10.1002/2013JB010451

Cheng MK, Ries JC (2017) The unexpected signal in GRACE estimates of C20. J. Geodesy. https://doi.org/10.1007/s00190-016-0995-5

Davis JL, Elósegui P, Mitrovica JX, Tamisiea ME (2004) Climate-driven deformation of the solid Earth from GRACE and GPS. Geophys Res Lett 31:1-4. https://doi.org/10.1029/2004GL021435

Dobslaw H, Thomas M (2007) Simulation and observation of global ocean mass anomalies. J Geophys Res 112:C05040. https://doi. org/10.1029/2006JC004035

Dobslaw H, Bergmann-Wolf I, Dill R et al (2017) A new high-resolution model of non-tidal atmosphere and ocean mass variability for de-aliasing of satellite gravity observations: aOD1B RL06. Geophys J Int 211:263-269. https://doi.org/10.1093/GJ/GGX302

Dong D, Yunck T, Heflin M (2003) Origin of the international terrestrial reference frame. J Geophys Res Solid Earth 108:1-10. https://doi. org/10.1029/2002jb002035

Eichler TP, Londoño AC (2013) South American climatology and impacts of El Niño in NCEP's CFSR data. Adv Meteorol. https://doi. org/10.1155/2013/492630

Farrell WE (1972) Deformation of the Earth by surface loads. Rev Geophys 10:761. https://doi.org/10.1029/RG010i003p00761

Ferreira VG, Montecino HC, Ndehedehe CE et al (2018) Space-based observations of crustal deflections for drought characterization in Brazil. Sci Total Environ 644:256-273. https://doi.org/10.1016/j.scitotenv.2018.06.277

Ferreira V, Ndehedehe C, Montecino H et al (2019) Prospects for imaging terrestrial water storage in South America using daily GPS observations. Remote Sens 11:679. https://doi.org/10.3390/rs11060679

Flament N, Gurnis M, Müller RD et al (2015) Influence of subduction history on South American topography. Earth Planet Sci Lett 430:9-18. https://doi. org/10.1016/j.epsl.2015.08.006

Fu Y, Freymueller JT (2012) Seasonal and long-term vertical deformation in the Nepal Himalaya constrained by GPS and GRACE measurements. J Geophys Res Solid Earth 117:1-14. https://doi.org/10.1029/2011JB008925

Fu Y, Freymueller JT, Jensen T (2012) Seasonal hydrological loading in southern Alaska observed by GPS and GRACE. Geophys Res Lett. https://doi. org/10.1029/2012gl052453

Galván R, Gende M, Brunini C (2015) Regional model to estimate vertical deformations due to loading seasonal changes. In: Rizos C, (eds) IAG 150 Years. International Association of Geodesy Symposia

Gelaro R, McCarty W, Suárez MJ et al (2017) The modern-era retrospective analysis for research and applications, version 2 (MERRA-2). J Clim 30:5419-5454. https://doi.org/10.1175/JCLI-D-16-0758.1

Gérard P, Luzum B (2010) IERS conventions. In: Bureau International des Poids et Mesures, pp 1-179

Getirana A (2016) Extreme water deficit in brazil detected from space. J Hydrometeorol 17:591-599. https://doi.org/10.1175/JHM-D-15-0096.1

Gu Y, Yuan L, Fan D et al (2017) Seasonal crustal vertical deformation induced by environmental mass loading in mainland China derived from GPS,
GRACE and surface loading models. Adv Sp Res 59:88-102. https://doi. org/10.1016/j.asr.2016.09.008

Hai-hua L, Min Z, Xu-hua Z (2010) Climate-driven annual vertical deformation of the solid earth calculated from GRACE. Chinese J Geophys 53:321-328. https://doi.org/10.3969/j.issn.0001-5733.2010.05.009

Hao M, Freymueller JT, Wang Q et al (2016) Vertical crustal movement around the southeastern Tibetan Plateau constrained by GPS and GRACE data. Earth Planet Sci Lett 437:1-8. https://doi.org/10.1016/j.epsl.2015.12.038 Hinze WJ, von Frese RRB, Longacre MB et al (1982) Regional magnetic and gravity anomalies of South America. Geophys Res Lett 9:314-317. https:// doi.org/10.1029/GL009i004p00314

Horne JH, Baliunas SL (1986) A prescription for period analysis of unevenly sampled time series. Astrophys J 302:757. https://doi.org/10.1086/164037

Hughes M, Hall A, Fovell RG (2009) Blocking in areas of complex topography, and its influence on rainfall distribution. J Atmos Sci 66:508-518. https:// doi.org/10.1175/2008JAS2689.1

Humphrey V, Gudmundsson L, Seneviratne SI (2016) Assessing global water storage variability from GRACE: trends, seasonal cycle, subseasonal anomalies and extremes. Surv Geophys 37:357-395

Jin S, Zhu W (2003) Contemporary crustal motion and deformation of south America plate. Geo-spatial Informait Sci 6:8-12. https://doi.org/10.1007/ BF02826747

Jin S, Wu Y, Heinkelmann R, Park J (2008) Diurnal and semidiurnal atmospheric tides observed by co-located GPS and VLBI measurements. J Atmos SolarTerrestrial Phys 70:1366-1372. https://doi.org/10.1016/j.jastp.2008.04.005

Khazaradze G, Klotz J (2003) Short- and long-term effects of GPS measured crustal deformation rates along the south central Andes. J Geophys Res 108:1-15. https://doi.org/10.1029/2002JB001879

Kusche JJ (2007) Approximate decorrelation and non-isotropic smoothing of time-variable GRACE-type gravity field models. J Geod 81:733-749. https ://doi.org/10.1007/s00190-007-0143-3

Li Z, Dam T van, Collilieux X, et al (2015) Quality evaluation of the weekly vertical loading effects induced from continental water storage models. In: IAG 150 Years. International Association of Geodesy Symposia, pp 243-255

Li W, van Dam T, Li Z, Shen Y (2016) Annual variation detected by GPS, GRACE and loading models. Stud Geophys Geod 60:608-621. https://doi. org/10.1007/s11200-016-0205-1

Melnick D, Moreno M, Quinteros J et al (2017) The super-interseismic phase of the megathrust earthquake cycle in Chile. Geophys Res Lett 44:784-791. https://doi.org/10.1002/2016GL071845

Moreira DM, Calmant S, Perosanz F et al (2016) Comparisons of observed and modeled elastic responses to hydrological loading in the Amazon basin. Geophys Res Lett 43:9604-9610. https://doi.org/10.1002/2016GL070265

Nahmani S, Bock O, Bouin MN et al (2012) Hydrological deformation induced by the West African Monsoon: Comparison of GPS, GRACE and loading models. J Geophys Res Solid Earth. https://doi.org/10.1029/201 1jb009102

Novello VF, Cruz FW, Moquet JS et al (2018) Two millennia of south Atlantic convergence zone variability reconstructed from isotopic proxies. Geophys Res Lett 45:5045-5051. https://doi.org/10.1029/2017GL076838

Pan Y, Shen W-B, Hwang C et al (2016) Seasonal mass changes and crustal vertical deformations constrained by GPS and GRACE in Northeastern Tibet. Sensors 16:1211. https://doi.org/10.3390/s16081211

Petrov L (2015) The International Mass Loading Service. In: International Association of Geodesy Symposia, pp 2006-2007

Ramillien G, Biancale R, Gratton S et al (2011) GRACE-derived surface water mass anomalies by energy integral approach: application to continental hydrology. J Geod 85:313-328. https://doi.org/10.1007/s0019 0-010-0438-7

Ray J, Crump D, Chin M (2007) New global positioning system reference station in Brazil. GPS Solut 11:1-10. https://doi.org/10.1007/s1029 $1-006-0032-x$

Rebischung P, Griffiths J, Ray J et al (2012) IGS08: the IGS realization of ITRF2008. GPS Solut 16:483-494. https://doi.org/10.1007/s1029 1-011-0248-2

Reichle RH, Koster RD, De Lannoy GJM et al (2011) Assessment and enhancement of MERRA land surface hydrology estimates. J Clim 24:6322-6338. https://doi.org/10.1175/JCLI-D-10-05033.1

Rienecker MM, Suarez MJ, Gelaro R et al (2011) MERRA: nASA's modern-era retrospective analysis for research and applications. J Clim 24:3624-3648. https://doi.org/10.1175/JCLI-D-11-00015.1 
Rodell M, Houser PR, Jambor U et al (2004) The global land data assimilation system. Bull Am Meteorol Soc 85:381-394. https://doi.org/10.1175/ BAMS-85-3-381

Rodell M, Famiglietti JS, Wiese DN et al (2018) Emerging trends in global freshwater availability. Nature 557:651-659. https://doi.org/10.1038/ s41586-018-0123-1

Sánchez L, Drewes H (2016) Crustal deformation and surface kinematics after the 2010 earthquakes in Latin America. J Geodyn 102:1-23. https://doi. org/10.1016/j.jog.2016.06.005

Save H, Tapley B, Bettadpur S, the CSR Level-2 Team (2018) GRACE RL06 reprocessing and results from CSR. In: Geophysical Research Abstracts, European Geoscience Union, vol 20, pp 10697-10701. EGU2018-10697

Scherneck H (1991) A parametrized solid earth tide model and ocean tide loading effects for global geodetic baseline measurements. Geophys J Int 106:677-694. https://doi.org/10.1111/j.1365-246X.1991.tb06339.x

Solman SA (2013) Regional climate modeling over South America: a review. Adv Meteorol 2013:1-13. https://doi.org/10.1155/2013/504357

Sun T, Ferreira V, He X, Andam-Akorful S (2016a) Water availability of São Francisco river basin based on a space-borne geodetic sensor. Water 8:213. https://doi.org/10.3390/w8050213

Sun Y, Riva R, Ditmar P (2016b) Optimizing estimates of annual variations and trends in geocenter motion and $\mathrm{J} 2$ from a combination of GRACE data and geophysical models. J Geophys Res Solid Earth. https://doi. org/10.1002/2016jb013073

Swenson S, Wahr J (2006) Post-processing removal of correlated errors in GRACE data. Geophys Res Lett 33:L08402. https://doi.org/10.1029/2005G L025285

Swenson S, Chambers D, Wahr J (2008) Estimating geocenter variations from a combination of GRACE and ocean model output. J Geophys Res 113:1-12. https://doi.org/10.1029/2007JB005338
Tan W, Dong D, Chen J, Wu B (2016) Analysis of systematic differences from GPS-measured and GRACE-modeled deformation in Central Valley, California. Adv Sp Res 57:19-29. https://doi.org/10.1016/j.asr.2015.08.034

Thomas M (2002) Ocean induced variations of Earth's rotation-results from a simultaneous model of global circulation and tides. Universität Hamburg, Hamburg

Tiwari VMM, Srinivas N, Singh B (2014) Hydrological changes and vertical crustal deformation in south India: inference from GRACE, GPS and absolute gravity data. Phys Earth Planet Inter 231:74-80. https://doi.org/10.1016/j. pepi.2014.03.002

Tregoning P, Watson C, Ramillien G et al (2009) Detecting hydrologic deformation using GRACE and GPS. Geophys Res Lett 36:1-6. https://doi. org/10.1029/2009GL038718

van Dam T, Ray R (2010) S1 and S2 atmospheric tide loading effects for geodetic applications. http://geophy.uni.lu/ggfc-atmosphere/tide-loadi ng-calculator.html. Accessed 7 July 2019

van Dam T, Wahr J, Lavallée D (2007) A comparison of annual vertical crustal displacements from GPS and Gravity Recovery and Climate Experiment (GRACE) over Europe. J Geophys Res Solid Earth 112:1-11. https://doi. org/10.1029/2006JB004335

Velicogna I, Wahr J, Van den Dool H (2001) Can surface pressure be used to remove atmospheric contributions from GRACE data with sufficient accuracy to recover hydrological signals? J Geophys Res 106:16415. https ://doi.org/10.1029/2001JB000228

\section{Publisher's Note}

Springer Nature remains neutral with regard to jurisdictional claims in published maps and institutional affiliations.

\section{Submit your manuscript to a SpringerOpen ${ }^{\circ}$ journal and benefit from:}

- Convenient online submission

- Rigorous peer review

- Open access: articles freely available online

- High visibility within the field

- Retaining the copyright to your article

Submit your next manuscript at $\boldsymbol{\nabla}$ springeropen.com 